\title{
Orostachys japonicus induces apoptosis and cell cycle arrest through the mitochondria-dependent apoptotic pathway in AGS human gastric cancer cells
}

\author{
DEOK-SEON RYU ${ }^{1}$, SEON-HEE KIM ${ }^{2}$, JI-HAE KWON ${ }^{2}$ and DONG-SEOK LEE ${ }^{1,2}$ \\ ${ }^{1}$ Department of Biomedical Laboratory Science, Inje University; ${ }^{2}$ Department of Smart Foods and \\ Drugs, Graduate School of Inje University, Gimhae, Gyungnam 621-749, Republic of Korea
}

Received February 11, 2014; Accepted April 7, 2014

DOI: 10.3892/ijo.2014.2404

\begin{abstract}
We investigated the anticancer mechanisms of the ethylacetate (EtOAc) fraction from Orostachys japonicus in human gastric cancer (AGS) cells. Flow cytometric analysis revealed that the number of total apoptotic cells following treatment with the EtOAc fraction increased in a dose-dependent manner. In the cell cycle analyses, the EtOAc fraction increased the peak in the sub-G1, indicating apoptosis, and in the $\mathrm{G}_{2} / \mathrm{M}$ phases in a dose-dependent manner. In the RT-PCR analysis, the expression of cyclin-dependent kinase 1 (CDK 1) and cyclin B1 decreased in a dose- and time-dependent manner. The results of western blotting revealed that the protein levels of p53, cytochrome c, and cleaved caspase-3, -8 and -9 proteins increased and those of B cell lymphoma-2 (bcl-2) and pro-caspase-3, -8 and -9 proteins decreased in a dose- and time-dependent manner, whereas the levels of bcl-2-associated x protein (bax) remained unchanged. Furthermore, the changes in the levels of pro-caspase-3, -8 and -9 and cleaved caspase-3, -8 and -9 were abolished by the pan-caspase inhibitor Z-VAD-FMK. In addition, phosphorylation of p38 and JNK increased in a time-dependent manner. These results, for the first time, provide an understanding of the potential anticancer activity of the $O$.japonicus, which functions through the induction of apoptosis and cell cycle arrest.
\end{abstract}

\section{Introduction}

The incidence of cancer is increasing dramatically, and currently, there is a strong emphasis on identifying biologically active substances from traditional herbs with anticancer properties, because these are believed to have fewer side

Correspondence to: Professor Dong-Seok Lee, Department of Biomedical Laboratory Science, Inje University, 607 Obang-dong, Gimhae, Gyungnam 621-749, Republic of Korea

E-mail: mbdslee@inje.ac.kr

Key words: Orostachys japonicus, AGS human gastric cancer cells, apoptosis, cell cycle arrest, MAPKs effects than conventional chemotherapeutic agents $(1,2)$. Orostachys japonicus, a perennial herbaceous plant belonging to the family Crassulaceae and referred to as Wa-song in Korea, has been used traditionally as an anti-inflammatory, anti-febrile, hemostatic, antidote and anticancer agent (3-7). In a previous study (8), dried powder of $O$. japonicus was extracted and fractionated using a series of organic solvents, including n-hexane (hexane), dichloromethane (DCM), ethylacetate (EtOAc), n-butanol $(\mathrm{BuOH})$, and water $\left(\mathrm{H}_{2} \mathrm{O}\right)$. These extracts were examined for their anticancer activities on various cancer cell lines, including human AGS gastric, A549 lung, HepG2 liver, and HT-29 colon cancer cells. Among the different $O$. japonicus fractions tested, the EtOAcsoluble fraction showed the highest anticancer activity against 4 cancer cell lines, among which, AGS showed the strongest effect. Furthermore, our previous study identified kaempferol, quercetin, and gallic acid in the EtOAc fraction (8). However, further research on $O$. japonicus is required considering the lack of fundamental data on the signaling pathways related to its physiological activity.

Apoptosis, the process of programmed cell death, is essential to maintain the normal development of organs and for the persistence of tissues in multi-cellular organisms. Failure of the apoptosis regulatory machinery is known to induce cancer or other degenerative diseases (4). Therefore, the rate of apoptosis in cancer cells is considered a principal indicator of anticancer activity. In cancer, cells continue to proliferate in an uncontrolled manner owing to their inability to sustain normal cellular activity (9). The level of cell cycle arrest has also been used as an indicator of anticancer activity. The p53 gene is a well-known transcription factor and a tumor suppressor gene that participates in several cellular processes, including apoptosis, cell signaling pathway, and cell cycle control. If cell DNA is damaged by extracellular stress, p53 is activated and moves to the nucleus, where it activates target genes. p53 activates genes involved in apoptosis and genes encoding cell division suppressors, thereby inducing apoptosis and suppressing cell division $(10,11)$. During apoptosis, phosphatidylserine (PS) is exposed to the outer membrane. This results in impeding antiapoptosis factors such as B cell lymphoma-2 (bcl-2), regulation of pro-apoptosis factors such as bcl-2 associated $\mathrm{x}$ protein (bax), release of mitochondria-mediated apoptosis factors such 
as cytochrome c, and activation of apoptosis-induced proteins such as caspase $(12,13)$. Many therapeutic substances with anticancer activity arrest the cell cycle and simultaneously induce apoptotic cell death (14). Defects in the regulation of the cell cycle are common causes of abnormal proliferation of cancer cells; therefore, studies of the cell cycle and cancer have become closely interconnected (15). The eukaryotic cell cycle is traditionally divided into 4 sequential phases: $\mathrm{G} 1, \mathrm{~S}, \mathrm{G}_{2}$ and $\mathrm{M}$. The cell cycle is regulated by cyclin/cyclin-dependent kinase (CDK) complexes (16). Mitogen activated protein kinases (MAPKs) are important mediators involved in the intracellular network of interacting proteins that transduce extracellular signals to intracellular responses. When MAPKs such as p38, c-Jun N-terminal kinase (JNK), and extracellular regulated protein kinase $1 / 2(E R K 1 / 2)$ are activated, their signals lead to the activation of diverse molecules that regulate proliferation, gene expression, differentiation, mitosis, cell survival and apoptosis $(17,18)$.

In this study, the effect of the EtOAc fraction derived from $O$. japonicus on the activation of signaling pathways involving p53 and its downstream and upstream effectors was investigated.

\section{Materials and methods}

Cell line and reagents. The EtOAc fraction was prepared from $O$. japonicas in our laboratory using methods described previously $(5,8,19,20)$. After analyzing the EtOAc fraction by GC-MS system, 12 peaks were identified. Nine peaks were unknown, and 3 peaks were identified as gallic acid (4.24\%), kaempferol (6.81\%) and quercetin (5.08\%) (8). AGS cells were obtained from the Korean cell line bank (KCLB, Seoul, Korea). Dulbecco's modified Eagle's medium (DMEM), fetal bovine serum (FBS), penicillin and streptomycin were purchased from Hyclone (Thermo Scientific, Logan, UT, USA). Monoclonal antibodies against p53; bcl-2; bax; cytochrome c; caspase-3, -8 and -9 ; cleaved caspase-3, -8 and -9; phospho-p38 (p-p38), -JNK (p-JNK), -ERK1/2 (p-ERK1/2); p38; JNK; ERK1/2; and glyceraldehyde-3-phosphate dehydrogenase (GAPDH) were obtained from Cell Signaling Technology (Berverly, MA, USA). Goat anti-rabbit IgG-horseradish peroxidase (HRP) secondary antibody was obtained from Santa Cruz Biotechnology (Santa Cruz, CA, USA). Z-VAD-FMK (a pancaspase inhibitor) was purchased from BD Pharmingen ${ }^{\text {TM }}$ (BD Biosciences, Franklin Lakes, NJ, USA). All other reagents used were of the highest available grade.

Cell culture. The AGS cells were cultured in DMEM containing $10 \% \mathrm{FBS}$ and $1 \%$ penicillin/streptomycin and incubated at $37^{\circ} \mathrm{C}$ in a $5 \% \mathrm{CO}_{2}$ incubator. The cells were subcultured every 5-7 days at 1:5 split ratios, and the culture medium was changed every 2 days. The cells at $\sim 80-90 \%$ confluency were used in the experiments. Cells were treated either with $0.1 \%$ dimethyl sulfoxide (DMSO) or with various concentrations of the EtOAc fraction for $12 \mathrm{~h}$.

Flow cytometric analysis of apoptosis. Apoptosis in the AGS cells was evaluated by Annexin V-fluorescein isothiocyanate (Annexin V-FITC) and propidium iodide (PI) staining by using the Annexin V-FITC apoptosis detection kit (BD Biosciences), according to the manufacturer's instructions. AGS cells $\left(4 \times 10^{5}\right.$ cells $/ \mathrm{ml}$ in a 24 -well plate) were added to different concentrations of the EtOAc fraction for $12 \mathrm{~h}$ and then harvested by centrifugation at $300 \mathrm{x} \mathrm{g}$. After centrifugation, the pellets were washed twice with cold phosphate-buffered saline (PBS; $137 \mathrm{mM} \mathrm{NaCl}, 2.7 \mathrm{mM} \mathrm{KCl}, 10 \mathrm{mM} \mathrm{Na}_{2} \mathrm{HPO}_{4}$, $\mathrm{pH}$ 7.4) and suspended in $100 \mu \mathrm{l}$ of $1 \mathrm{X}$ binding buffer $(10 \mathrm{mM}$ HEPES/NaOH, $140 \mathrm{mM} \mathrm{NaCl}, 2.5 \mathrm{mM} \mathrm{CaCl}_{2}, \mathrm{pH}$ 7.4). The cells were incubated with $5 \mu \mathrm{l}$ of Annexin V-FITC and $5 \mu \mathrm{l}$ of PI at the room temperature for 15 min in the dark. After incubation, $400 \mu \mathrm{l}$ of $1 \mathrm{X}$ binding buffer was added to each tube and the cells were analyzed immediately by FACSCalibur flow cytometry (Becton Dickinson, Franklin Lakes, NJ, USA).

Flow cytometric analysis of the cell cycle. The cell cycle phase was assayed by DNA fragment staining with PI using the Cell Cycle Phase determination kit (Cayman Chemical, MI, USA), according to the manufacturer's instructions. AGS cells $\left(4 \times 10^{5}\right.$ cells $/ \mathrm{ml}$ in a 24 -well plate) were added to different concentrations of the EtOAc fraction for $12 \mathrm{~h}$ and then harvested. After centrifugation, the pellets were washed and suspended in cell-based assay buffer. The cells were fixed and permeabilized by adding $1 \mathrm{ml}$ of a fixative to each tube for more than $2 \mathrm{~h}$. After centrifugation, the fixatives were decanted and the cell pellets were suspended in $500 \mu \mathrm{l}$ of a staining solution (200 $\mu \mathrm{l}$ of RNase and $200 \mu \mathrm{l}$ of PI), followed by incubation for $30 \mathrm{~min}$ at room temperature in the dark. Then, the cells were analyzed immediately by FACSCalibur flow cytometry.

RT-PCR analysis. Total RNA was isolated using TRI reagent (Sigma-Aldrich, St. Louis, MO, USA). The cells were lysed using the TRI reagent, followed by the addition of chloroform (Sigma-Aldrich). RNA precipitated by 2-propanol (SigmaAldrich). The purity and concentration of the total RNA was checked by Optizen 2120 UV plus spectrophotometer (Mecasys Co., Ltd., Daejeon, Korea). Equal amounts of RNA were reverse-transcribed into cDNA using the DiaStar ${ }^{\mathrm{TM}} \mathrm{RT}$ kit (Solgent Co., Ltd., Daejeon, Korea) by incubation at $65^{\circ} \mathrm{C}$ for $5 \mathrm{~min}, 50^{\circ} \mathrm{C}$ for $60 \mathrm{~min}$, and $95^{\circ} \mathrm{C}$ for $5 \mathrm{~min}$. PCR was performed using a $50 \mu \mathrm{l}$ reaction mixture containing cDNA, 10X h-Taq buffer, $10 \mathrm{mM}$ dNTP mix, $10 \mathrm{pM}$ of each primer, h-Taq polymerase (Solgent Co., Ltd.), and RNase-free water. Primers used for amplification were as follows: i) CDK1: forward 5'-TTTTCAGAGCTTTGGGCACT-3' and reverse 5'-AAACATGGCAGTGACACCAA-3', ii) cyclin B1: forward 5'-CGGGAAGTCACTGGAAACAT-3' and reverse 5'-AAACA TGGCAGTGACACCAA-3', iii) GAPDH: forward 5'-GAGTC AACGGATTTGGTCGT-3' and reverse 5'-TTGATTTTGG AGGGAGCTCG-3'. The samples were subjected to 25 cycles of denaturation for $20 \mathrm{sec}$ at $95^{\circ} \mathrm{C}$, annealing for $40 \mathrm{sec}$ at $56^{\circ} \mathrm{C}$ (cyclin B1 and GAPDH) and $54^{\circ} \mathrm{C}(\mathrm{CDK} 1)$, extension for $1 \mathrm{~min}$ at $72^{\circ} \mathrm{C}$, and a final extension step at $72^{\circ} \mathrm{C}$ for $5 \mathrm{~min}$. The housekeeping gene GAPDH served as the control. The PCR products were electrophoresed in $2 \%$ agarose gel, followed by staining with $0.5 \mu \mathrm{g} / \mathrm{ml}$ ethidium bromide (EtBr) at $100 \mathrm{~V}$ for $30 \mathrm{~min}$ and visualization under a UV transilluminator.

Western blotting. The AGS cells were treated with the EtOAc fraction, washed twice with ice-cold PBS, and harvested using 

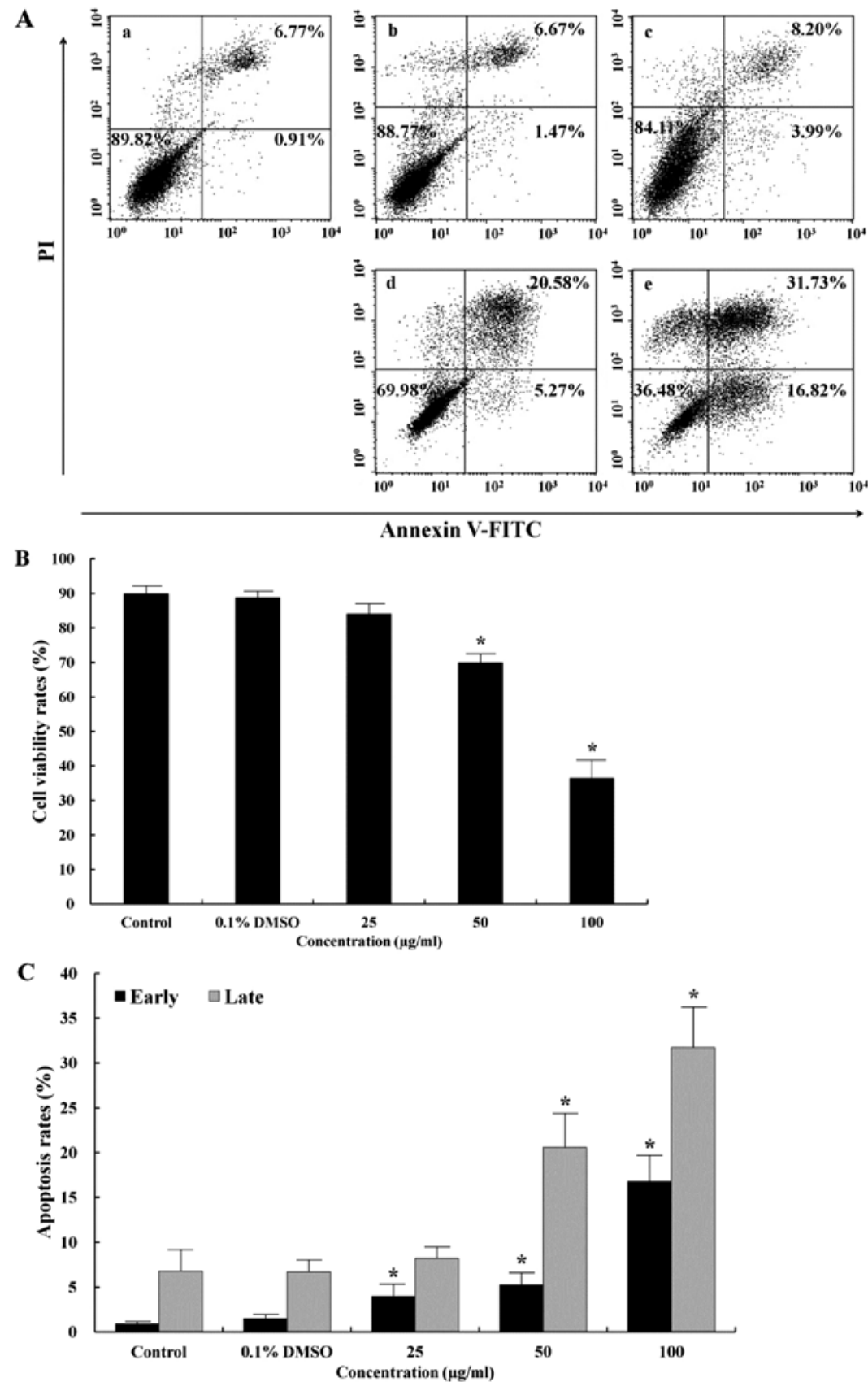

Figure 1. Flow cytometry analysis of the apoptotic death of AGS cells. (A) Dot plots display the apoptotic death of AGS cells treated without EtOAc fraction (a) or with $0.1 \%$ DMSO, 25, 50 and $100 \mu \mathrm{g} / \mathrm{ml}$ EtOAc fraction (b-e) for $12 \mathrm{~h}$. The cells were stained with monoclonal antibodies against Annexin V-FITC and PI. Percentages of (B) viable cells and (C) apoptotic cells are shown. The values are expressed as the mean \pm SD. Significantly different from control at * $\mathrm{p}<0.05$.

a cell scraper. The cells were then pelleted by centrifugation, the pellets were resuspended in lysis buffer on ice for $1 \mathrm{~h}$, and the cell debris was removed by centrifugation at $10,000 \mathrm{xg}$ for $10 \mathrm{~min}$. Protein concentrations were determined using the Bicinchoninic acid (BCA) Protein Assay kit (Thermo Scientific, Rockford, IL, USA). Equal amounts of protein were mixed with $2 \mathrm{X}$ Laemmli loading buffer and preheated at $95^{\circ} \mathrm{C}$ for $5 \mathrm{~min}$. The samples were electrophoresed on $10-15 \%$ sodium dodecyl sulfate (SDS)-polyacrylamide gels and transferred onto a polyvinylidene fluoride (PVDF) membrane for $1 \mathrm{~h}$ by using a semi-dry transfer system (Bio-Rad Laboratories, Hercules, CA, USA). The membrane was blocked with 5\% non-fat milk in PBS containing $0.1 \%$ Tween-20 (PBST) for $2 \mathrm{~h}$ at $4^{\circ} \mathrm{C}$ and then incubated overnight with primary antibodies. After hybridization with primary antibodies, the membranes were washed for $5 \mathrm{~min}$ with PBST, 3 times. The membranes were subsequently incubated with HRP-secondary antibody for $2 \mathrm{~h}$ at $4^{\circ} \mathrm{C}$ and washed for 5 min with PBST, 3 times. The signal of the membranes was developed by using a western blotting luminal reagent (Santa Cruz Biotechnology).

Statistical analysis. All experiments were performed at least 3 times. The data are expressed as the mean \pm standard deviation (SD). The statistical differences were calculated using the Student's t-test using the SigmaStat software (SigmaStat for Windows version 3.0.). A p-value of $<0.05$ was considered statistically significant. 

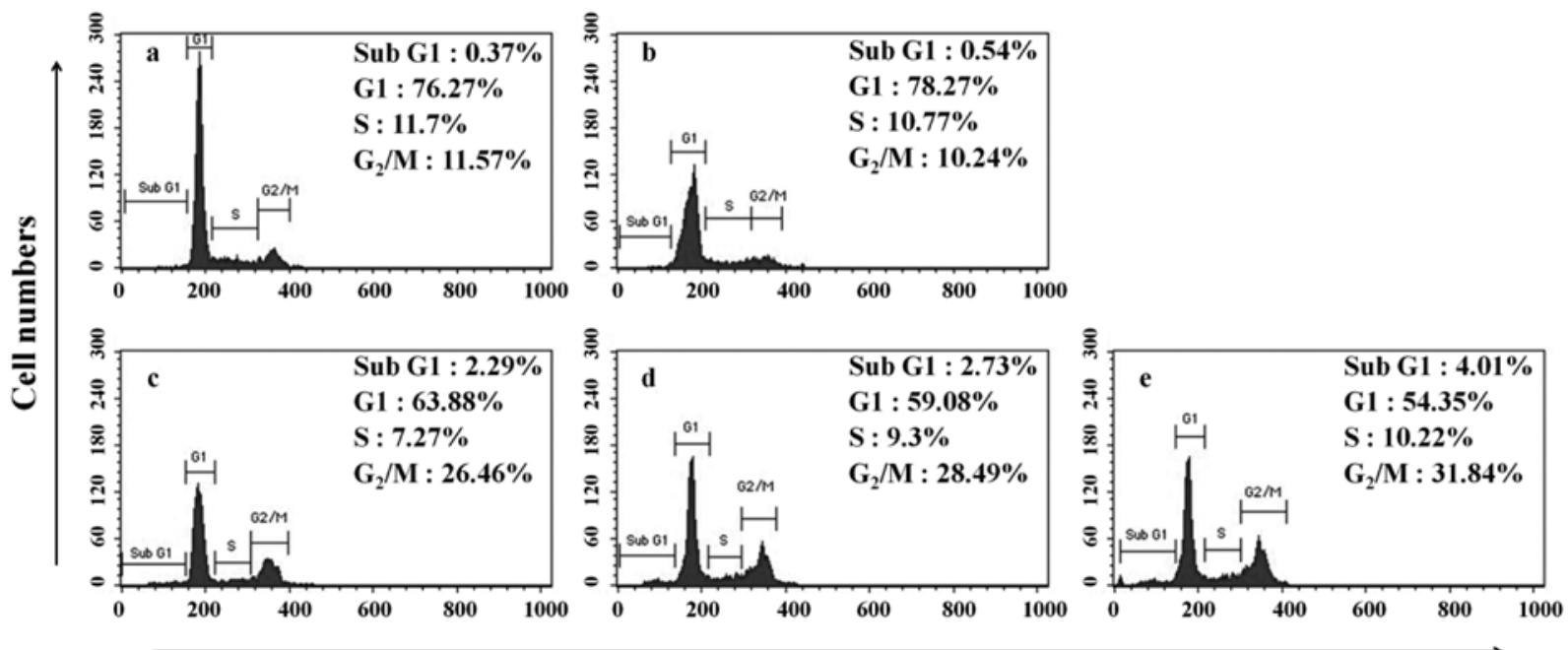

DNA contents

\begin{tabular}{ccccc}
\hline \hline $\begin{array}{c}\text { Control } \\
(\mu \mathrm{g} / \mathrm{ml})\end{array}$ & Sub $\mathrm{G}_{1}$ & $\mathrm{G}_{1}$ & $\mathrm{~S}$ & $\mathrm{G}_{2} / \mathrm{M}$ \\
\hline Control & $0.37 \pm 0.14$ & $76.08 \pm 1.35$ & $11.63 \pm 1.35$ & $11.39 \pm 2.88$ \\
$0.1 \%$ DMSO & $0.39 \pm 0.17$ & $76.83 \pm 2.27$ & $10.46 \pm 0.44$ & $12.02 \pm 2.35$ \\
25 & $2.25 \pm 0.19^{*}$ & $64.14 \pm 3.05^{*}$ & $8.26 \pm 1.02^{*}$ & $25.08 \pm 4.28^{*}$ \\
50 & $2.88 \pm 0.14^{*}$ & $59.17 \pm 1.13^{*}$ & $9.11 \pm 0.62$ & $28.47 \pm 2.01^{*}$ \\
100 & $4.57 \pm 0.51^{*}$ & $53.46 \pm 1.20^{*}$ & $10.05 \pm 1.56$ & $31.83 \pm 0.47^{*}$ \\
\hline
\end{tabular}

Figure 2. Flow cytometry analysis of cell cycle distribution of AGS cells. Histograms display sub G1, G1, S and $\mathrm{G}_{2} / \mathrm{M}$ phase of AGS cells without EtOAc fraction (a) or with $0.1 \%$ DMSO, 25, 50 and $100 \mu \mathrm{g} / \mathrm{ml}$ EtOAc fraction (b-e) for $12 \mathrm{~h}$. The results are presented as percentage of total treated cells. Data values are expressed as mean $\pm \mathrm{SD}$. $(\mathrm{n}=3)$. Significantly different from control at ${ }^{*} \mathrm{p}<0.05$.

\section{Results}

Induction of apoptosis. At the initial stages of apoptosis, the PS is exposed, which is considered an early marker of apoptosis. In addition, Annexin $\mathrm{V}$, a $\mathrm{Ca}^{2+}$-dependent phospholipid-binding protein, can now bind to the exposed PS (21). The exposed PS could be detected based on this characteristic. At the same time, the damaged DNA is stained using PI. Thus, from the amount of Annexin V binding and the intensity of PI staining, apoptosis can be detected. As shown in Fig. 1A, stained cell populations were defined as follows: lower left (LL), viable cells (Annexin $\mathrm{V}^{-} / \mathrm{PI}^{-}$); lower right (LR), cells undergoing early apoptosis (Annexin $\mathrm{V}^{+} / \mathrm{PI}^{-}$); upper right (UR), and late apoptotic or necrotic cells (Annexin $\mathrm{V}^{+} / \mathrm{PI}^{+}$). Apoptosis induction in AGS cells treated with the EtOAc fraction was evaluated by flow cytometry. The EtOAc fraction increased the number of early (LR) and late (UR) apoptotic cells in a dose-dependent manner (Fig. 1C). In addition, the total apoptosis rate was more than 6-fold higher than that in the control (48.55 vs. $7.68 \%$ ) (Fig. 1A). Under control conditions, $89.82 \%$ of cells were viable (LL). In contrast, the survival rate induced by the $100 \mu \mathrm{g} / \mathrm{ml}$ EtOAc fraction was $36.48 \%$ (Fig. 1B).

Induction of cell cycle arrest. The DNA content of the PI-stained AGS cells was determined by flow cytometry. The fragmented DNA that serves as evidence of apoptosis is manifested on the left side rather than at the G1 peak of a cell cycle (22). Apoptosis can be observed by detecting the presence of this sub-G1 peak. To probe the relationship between the inhibitory effect of the EtOAc fraction on AGS cell growth and the apoptotic effect, we investigated the alteration of the cell cycle using flow cytometry. In the control cells, this sub-G1 peak was negligible $(0.37 \%)$, but accounted for $4.57 \%$ of the cells treated with the $100 \mu \mathrm{g} / \mathrm{ml} \mathrm{EtOAc}$ fraction. The sub-G1 phase cell population of the EtOAc fraction-treated cells increased in a dose-dependent manner (Fig. 2). Further, apart from the sub-G1 peak as evidence of apoptosis, the $\mathrm{G}_{2} / \mathrm{M}$ peak was $31.83 \%$, simultaneously being measured at a significantly higher rate than that of the control $(11.39 \%)$. The $\mathrm{G}_{2} / \mathrm{M}$ phase cell population of the EtOAc fraction-treated cells increased in a dose-dependent manner. Depending on the control period of DNA synthesis, the cell cycle is divided into four phases: $\mathrm{G} 1, \mathrm{~S}, \mathrm{G}_{2}$ and $\mathrm{M}$. The cell cycle has a checkpoint that determines whether the general progress of cell division is implemented from one phase to another without disorder. The $\mathrm{G}_{2} / \mathrm{M}$ transition is a point at which the completion of DNA replication is confirmed prior to cell division (23). An increase in $\mathrm{G}_{2} / \mathrm{M}$ peak refers to the $\mathrm{G}_{2} / \mathrm{M}$ cell cycle arrest shows inhibited cell division, incapacitation by further cell division due to the damage in the DNA of the AGS cells.

Effect of the EtOAc fraction on the expression level of the cell cycle-related genes. As the EtOAc fraction arrested the 


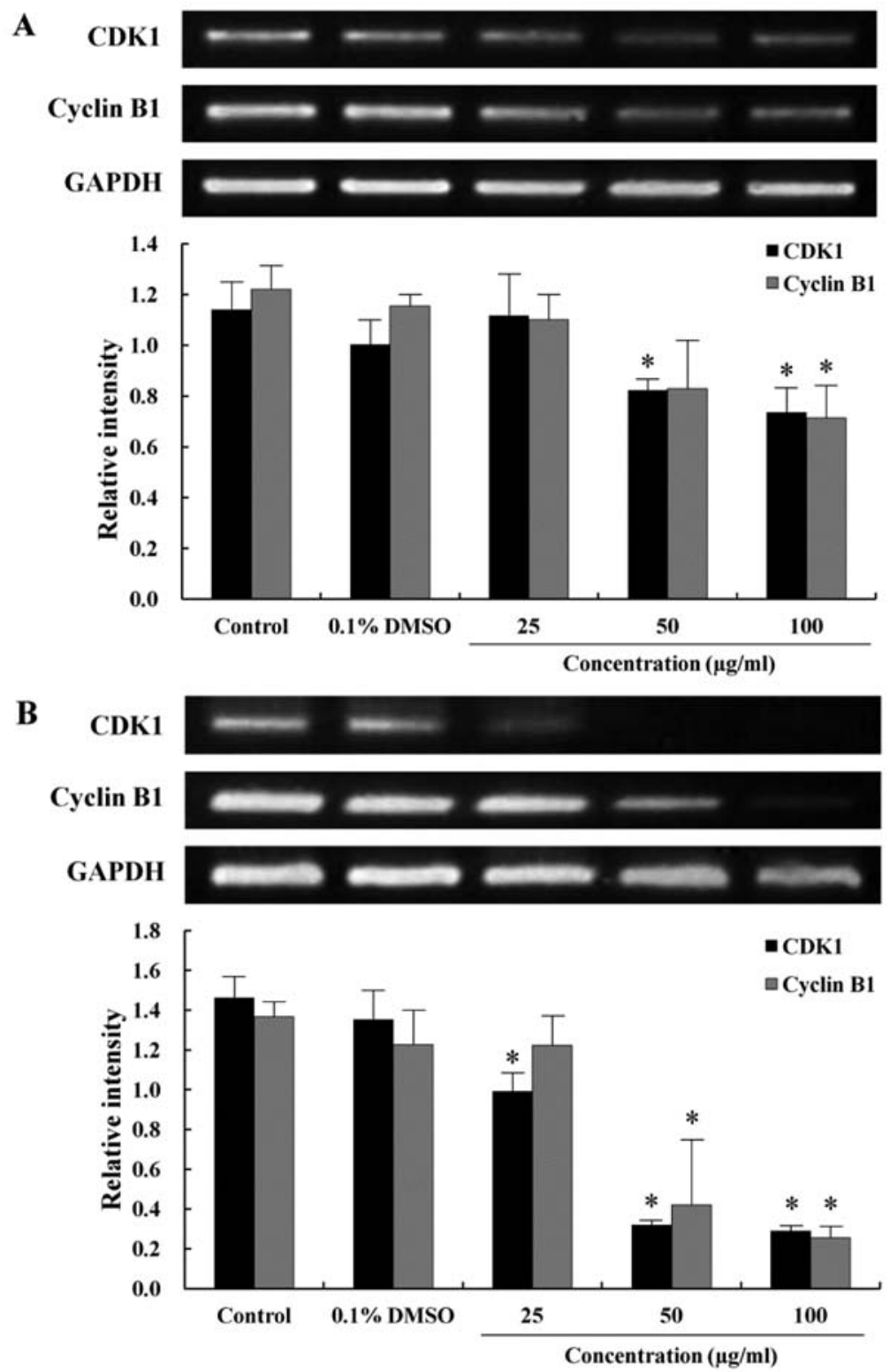

Figure 3. Effect of EtOAc fraction on mRNA expressions of CDK1 and cyclin B1 in AGS cells. The cells were treated with different concentration of EtOAc fraction for 6 or $12 \mathrm{~h}$ (A and B). Total RNAs were isolated from the cells and RT-PCR was performed. Band density was quantitated and plotted on the bar graph. GAPDH was used as a housekeeping control gene. The intensities of bands were determined by densitometry in three separate experiments with similar results. The values are expressed as the mean \pm SD. Significantly different from control at ${ }^{*} \mathrm{p}<0.05$.

AGS cells in the $\mathrm{G}_{2} / \mathrm{M}$ phase of the cell cycle, RT-PCR was performed to study the correlation between $\mathrm{G}_{2} / \mathrm{M}$ arrest and the transcription of the cell cycle-related genes. The CDK1 is primarily activated in association with cyclin $\mathrm{B} 1$ during the progression of the $\mathrm{G}_{2} / \mathrm{M}$ phase (24). To examine the expression of mRNA levels regulating the cell cycle progression at the $\mathrm{G}_{2} / \mathrm{M}$ phase, which was remarkably arrested as shown in Fig. 2, CDK1 and cyclin B1 expression were measured by RT-PCR. The expression of CDK1 decreased when the cells were treated with the EtOAc fraction in a time- and dosedependent manner (Fig. 3). Cyclin B1 was also expressed at a lower level in the EtOAc fraction-treated cells than in the control cells. The decrease in the expression of CDK1 and cyclin $B 1$ correlated to the increase in distribution of the $\mathrm{G}_{2} / \mathrm{M}$ peak, which was consistent with the $\mathrm{G}_{2} / \mathrm{M}$ arrest observed from the cell cycle analysis.
Induction of mitochondrial-mediated apoptosis. To further provide insight into the apoptotic effect of the EtOAc fraction, this study measured the expression level of p53, bcl-2, bax and cytochrome c proteins, which are relevant to the understanding of apoptotic signaling pathways after exposure to the EtOAc fraction for $12 \mathrm{~h}$ in the AGS cells. p53 is a tumor suppressor gene and transcription factor that induces either apoptosis or cell cycle arrest in response to extracellular stress signals and DNA damage (25). In addition, the imbalance of bcl-2 and bax protein expression could be influenced by p53 (26). The level of p53 protein expression increased in a dose-dependent manner (Fig. 4A). Major proteins involved in apoptosis are bcl-2 and bax. The bcl-2 protein inhibits the emission of cytochrome $\mathrm{c}$ from the mitochondria to defend the cell from apoptosis signals. In contrast, bax protein induces apoptosis by inducing stress in the mitochondria (27). The release of cytochrome $\mathrm{c}$ 
$\mathbf{A}$
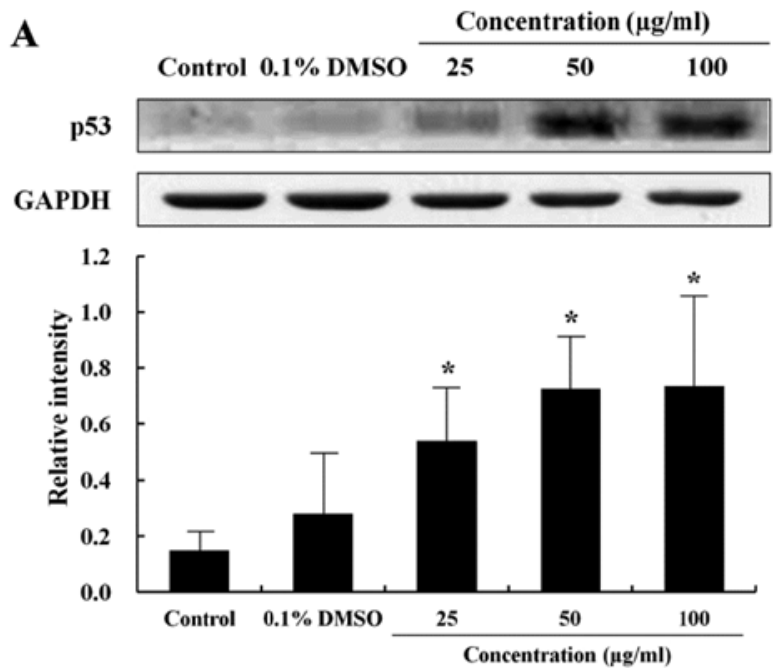

B

Concentration $(\mu \mathrm{g} / \mathrm{ml})$
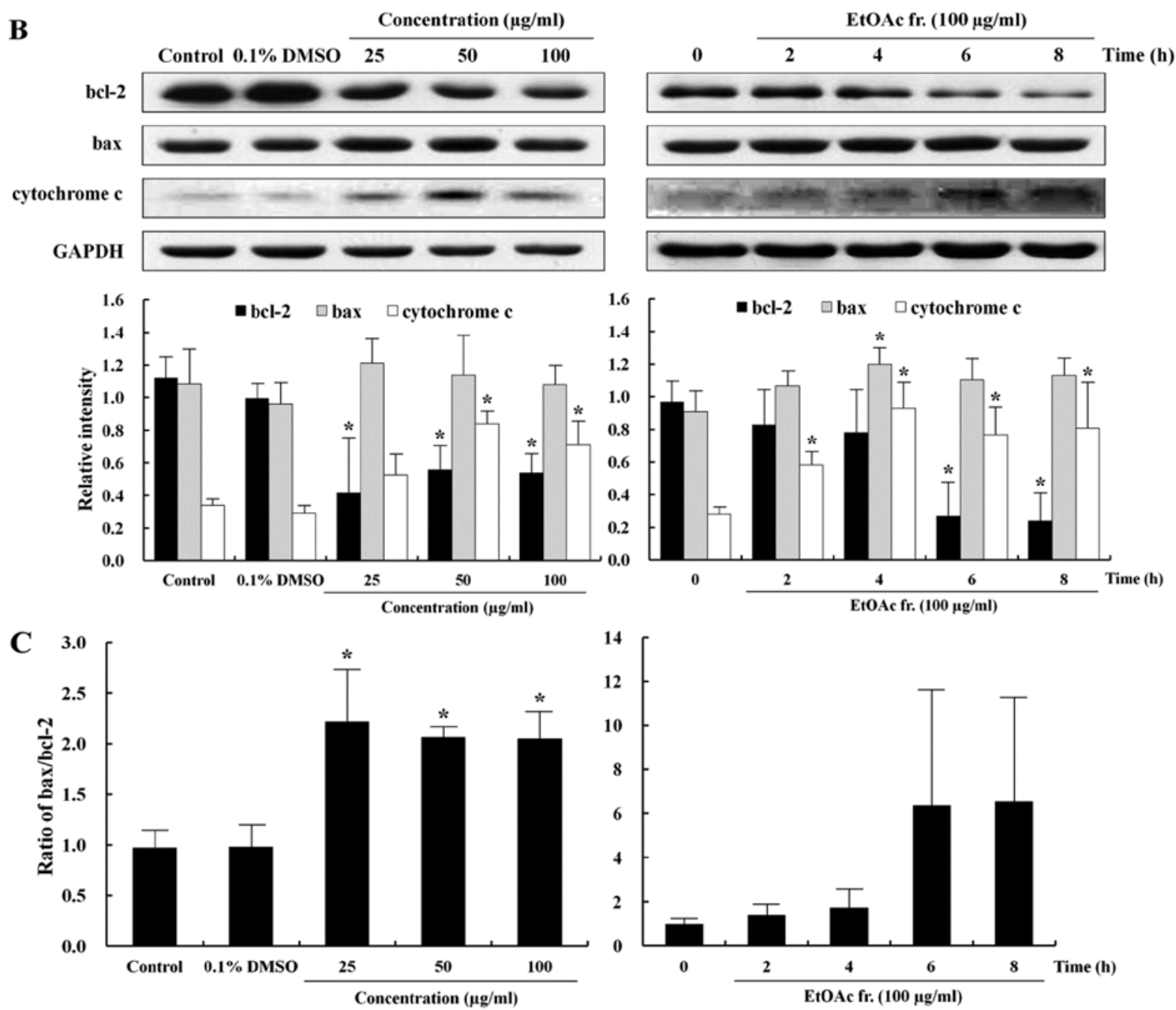

Figure 4. Effect of EtOAc fraction on protein expressions of p53, bcl-2, bax and cytochrome c in AGS cells. The cells were treated with different concentration of EtOAc fraction for $12 \mathrm{~h}$ or $100 \mu \mathrm{g} / \mathrm{ml}$ EtOAc fraction for indicated times. The expressions of (A) p53, (B) bcl-2, bax, and cytochrome c were analyzed by western blotting. Band density was quantitated and plotted on the bar graph. (C) Ratio of bax/bcl-2 level was determined by ImageJ analysis. p53, $53 \mathrm{kDa}$; bcl-2, $26 \mathrm{kDa}$; bax, $23 \mathrm{kDa}$; cytochrome c, $14 \mathrm{kDa}$. GAPDH was used as an internal control. The values are expressed as the mean \pm SD. Significantly different from control at ${ }^{*} \mathrm{p}<0.05$.

from the mitochondria is promoted by bax and blocked by bcl-2 (28). The levels of anti-apoptotic and apoptotic proteins were examined by western blotting to determine whether the EtOAc fraction induced the apoptosis of AGS cells through the regulation of bcl-2, bax and cytochrome c. The expression of bcl-2, bax and cytochrome c proteins in the AGS cells with the EtOAc fraction is shown in Fig. 4B. The level of bcl-2 protein expression decreased and that of cytochrome $\mathrm{c}$ increased in a 
time- and dose-dependent manner, while that of bax was not significantly different between the EtOAc fraction-treated cells and the control cells. However, the bax/bcl-2 ratios increased significantly in a dose-dependent manner (Fig. 4C). These results suggest that the EtOAc fraction induced apoptosis of the AGS cells via the mitochondrial-mediated pathway.

Induction of caspase-mediated apoptosis. The apoptotic pathway is regulated by caspases that are responsible, either directly or indirectly, for the cleavage of other protein substrates within the cell, which is a characteristic of apoptosis (29). Caspase- 3 is an effector caspase that can trigger the apoptotic process by activation of initiator caspases such as caspase- 8 and -9 (30). In order to understand the mechanisms involved in the caspase-mediated apoptosis, we measured the expression levels of pro-caspase-3, -8, -9 and cleaved caspase-3, -8, -9 proteins. The treatment of the AGS cell with the EtOAc fraction caused decreases in the levels of pro-caspase-3, -8 and -9 , inactive forms of caspase, in a time- and dose-dependent manner (Fig. 5A). The cleavage of caspases is directly related to the activation of the apoptotic process. Cleaved caspase-3, -8 and -9 , the active forms of caspase, increased substantially in the EtOAc fraction-treated AGS cells in a time- and dosedependent manner (Fig. 5A). To investigate whether apoptosis inductions was caspase-dependent, we used the general caspase inhibitor Z-VAD-FMK. As shown in Fig. 5B, the addition of $20 \mu \mathrm{M} Z$-VAD-FMK significantly reduced the induction of apoptosis in response to the EtOAc fraction in a dose-dependent manner. These results show that caspase- $3,-8$ and -9 act as fundamental factors in the apoptotic effect of the EtOAc fraction in the AGS cells.

Involvement of MAPKs in the induction of apoptosis. MAPKs, such as p38, JNK and ERK1/2, activated by extracellular signals are involved in pro-survival and pro-apoptotic activity (31). To understand the role of pro-survival- and proapoptotic-signaling pathways in the induction of apoptosis, this study assessed $100 \mu \mathrm{g} / \mathrm{ml}$ of the EtOAc fraction-treated AGS cells by western blotting using antibodies against the phosphorylated and total forms of MAPKs. Western blotting showed that the phosphorylation of p38 and JNK increased in the EtOAc fraction-treated AGS cells in a time-dependent manner. Activation of p38 and JNK was increased at $15 \mathrm{~min}$ and $30 \mathrm{~min}$, respectively, and continued to increase until $120 \mathrm{~min}$. On the other hand, activation of ERK1/2 increased markedly at $15 \mathrm{~min}$, but thereafter, it decreased until $120 \mathrm{~min}$ in a time-dependent manner (Fig. 6). The expression of the total forms of $\mathrm{p} 38, \mathrm{JNK}$ and ERK1/2 did not change.

\section{Discussion}

Our results showed that the EtOAc fraction induced apoptosis and cell cycle arrest in the AGS cells. The apoptosis of the AGS cells with the EtOAc fraction was induced by p53 and mitochondrial-mediated apoptotic proteins through the MAPK signaling pathway. In addition, the EtOAc fraction arrested the AGS cells in the $\mathrm{G}_{2} / \mathrm{M}$ phase of the cell cycle by regulating CDK1 and cyclin B1. In our previous study (8), we demonstrated that the EtOAc fraction, from among the 5 other fractions tested, possessed the highest anticancer activity in the AGS cells, as evidenced by 4'-6-diamidino2-phenylindole (DAPI) staining, DNA fragmentation assay and flow cytometry analysis. The present study is the first to investigate the signaling pathway at the molecular biological level in the context of exposure time and dose.

Apoptosis is the process of programmed cell death that is characterized by cell changes, including exposure of PS from the cell membrane and DNA fragmentation (32). To detect the characteristics of apoptosis in the AGS cells treated with the EtOAc fraction, flow cytometry analysis was performed following Annexin V/PI staining for detection of early or late apoptosis, and PI labeling assay was performed to detect DNA damage. As shown in Fig. 1, the early apoptosis rate $(16.82 \%)$ in the AGS cells treated with the $100 \mu \mathrm{g} / \mathrm{ml}$ EtOAc fraction was higher than that of the control $(0.91 \%)$, and the late apoptosis rate $(31.73 \%)$ was higher than that of the control $(6.77 \%)$. The EtOAc fraction increased the total apoptosis rate and decreased the survival rate in a dose-dependent manner. The fragmented DNA that indicated the induction of apoptosis observed in the sub-G1 peak of the cell cycle. The EtOAc fraction increased the sub-G1 phase cell population in a dose-dependent manner (Fig. 2). These results suggest that the EtOAc fraction may not only induce apoptosis, but also inhibit the growth of AGS cells.

The normal cell growth is regulated through cell cycle progression, and uncontrolled cell growth is a characteristic of cancer. Several anticancer agents have been reported to arrest the cell cycle and simultaneously induce apoptosis. Cell cycle arrest has been used as an indicator of anticancer activity (33). The eukaryotic cell cycle is divided into the G1 phase for DNA duplication, the synthetic $S$ phase for effective DNA duplication, the $\mathrm{G}_{2}$ phase for cell growth ready for mitosis, and the M phase for mitosis (34). There are 3 checkpoints that check the general progress for problem-free cell division with regular transition between the phases, i.e., in the late $\mathrm{G} 1$ phase, $\mathrm{G}_{2} / \mathrm{M}$ transition, and metaphase-to-anaphase transition (24). The CDKs are protein kinases involved in regulating the cell cycle and binding a regulatory protein called cyclin. The cyclin-CDK complexes regulate the general progress for a cell cycle. The cyclin D-CDK4 (and/or 6) complex is necessary for initiating the G1 phase, while the cyclin E-CDK2 complex is needed to progress to the $\mathrm{S}$ phase. The cyclin A-CDK2 complex is involved from $S$ to $G_{2}$ phase, and the cyclin B1-CDK1 complex is required for progression to the $M$ phase $(22,35)$. The effect of the EtOAc fraction on the cell cycle progression of the AGS cells is shown in Figs. 2 and 3 . The $\mathrm{G}_{2} / \mathrm{M}$ phase cell population of the EtOAc fraction-treated cells increased in a dose-dependent manner. In the present study, we investigated the correlation between $\mathrm{G}_{2} / \mathrm{M}$ arrest and the regulating genes of the cell cycle. Expression of CDK1 and cyclin B1 decreased comparison with the control in a time- and dose-dependent manner (Fig. 3). These results revealed that the EtOAc fraction act on the $\mathrm{G}_{2} / \mathrm{M}$ transition checkpoint of the cell cycle.

p53 is a tumor suppressor gene, a transcription factor, which becomes activated in the cytoplasm and accumulated in the nucleus when the DNA is damaged by extracellular stress. p53 activates the target genes, including those encoding apoptotic proteins and cell division suppressor genes to induce apoptosis and arrest the cell cycle (36). The basal level of p53 was low in the AGS cells, and the EtOAc fraction upregulated 

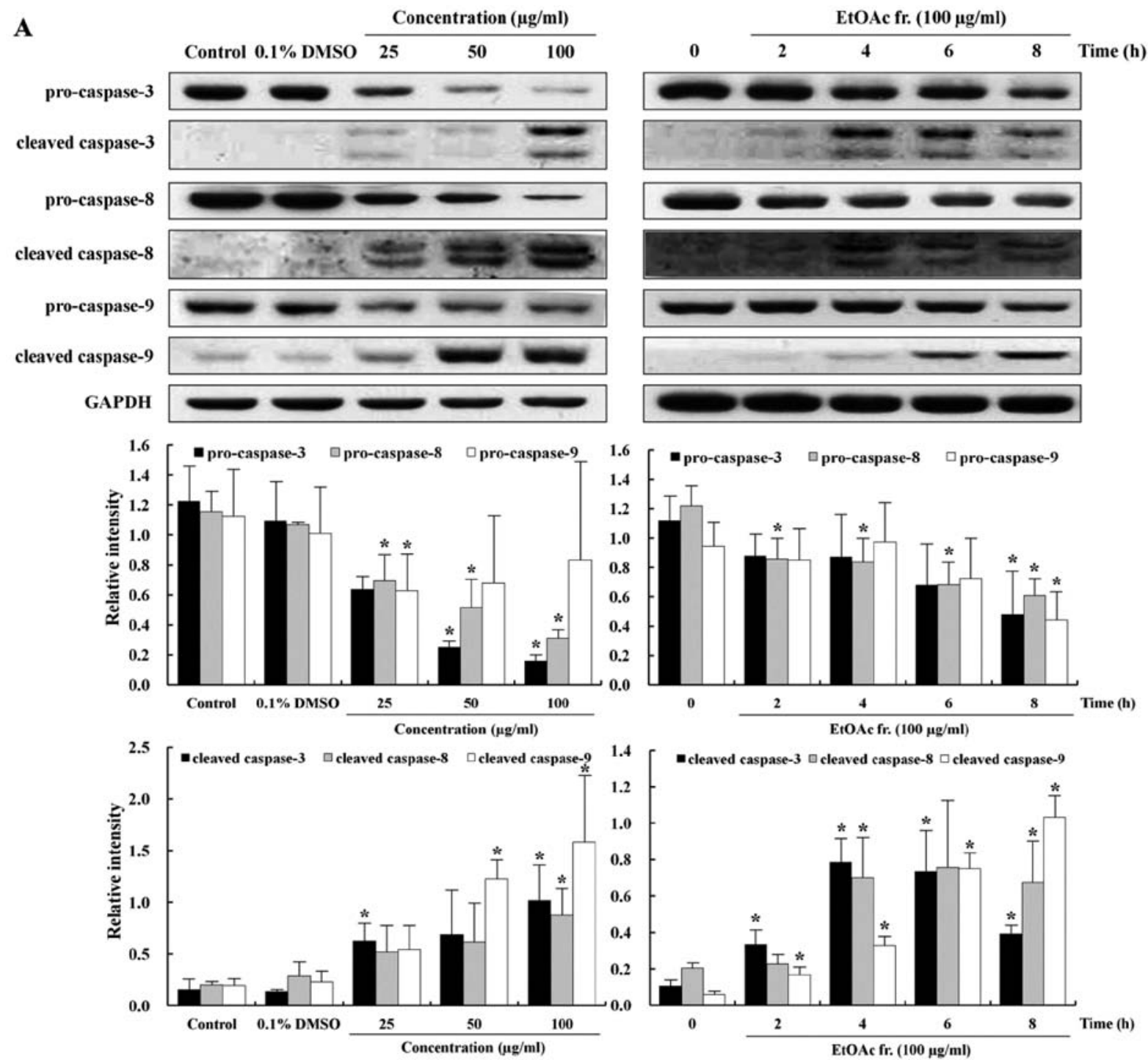

B
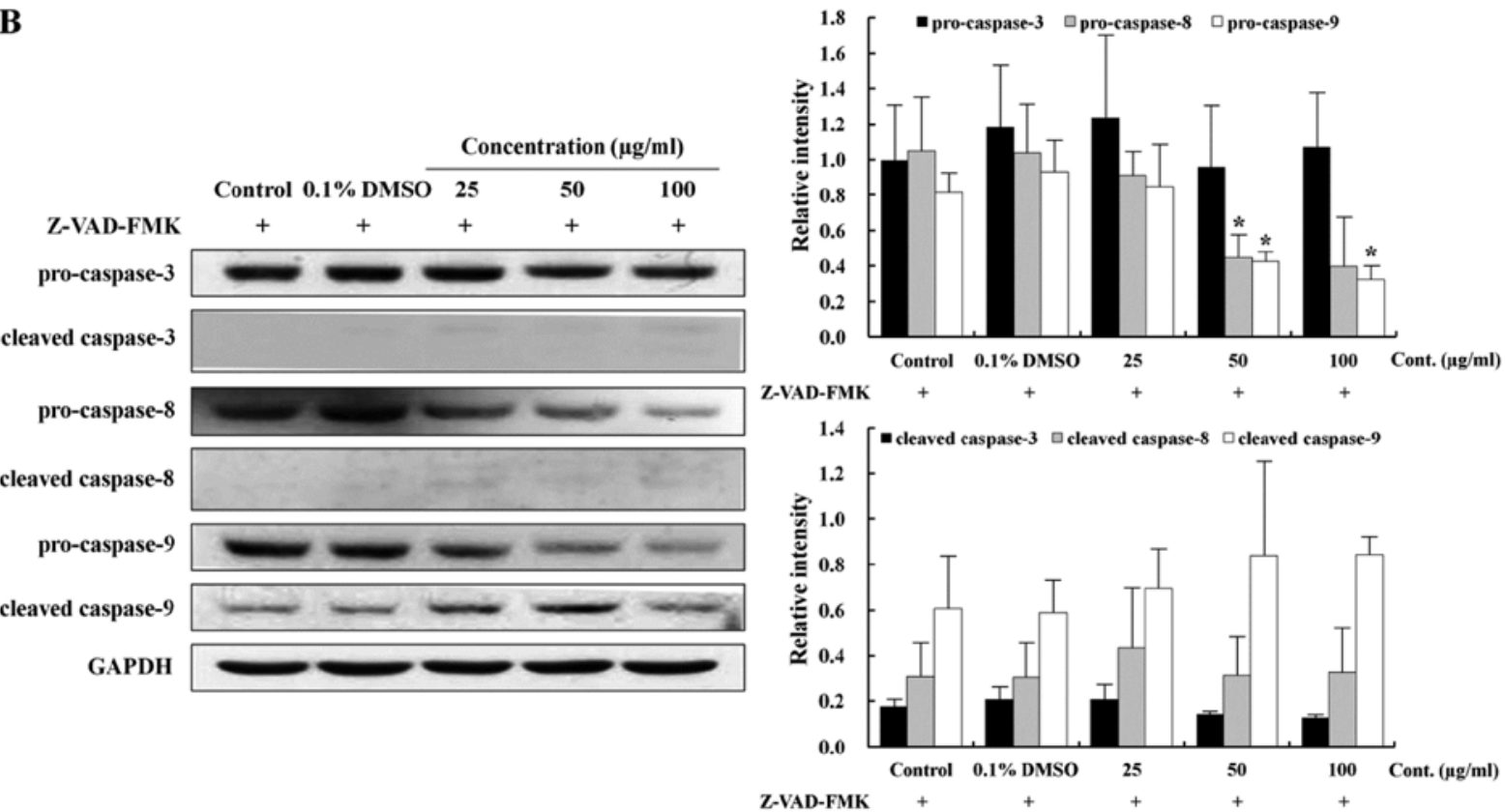

Figure 5. Effect of EtOAc fraction on protein expressions of caspase-3, -8 and -9 in AGS cells. (A) The cells were treated with different concentration of EtOAc fraction for $12 \mathrm{~h}$ or $100 \mu \mathrm{g} / \mathrm{ml}$ EtOAc fraction for indicated times. (B) The cells were pretreated with the pan-caspase inhibitor Z-VAD-FMK (20 $\mu \mathrm{M}$ ). Band density was quantitated and plotted on the bar graph. pro-caspase-3, $32 \mathrm{kDa}$; cleaved caspase-3, 17/19 kDa; pro-caspase-8, $57 \mathrm{kDa}$; cleaved caspase-8, $41 / 48 \mathrm{kDa}$; pro-caspase-9, $47 \mathrm{kDa}$; cleaved caspase-9, 35/37 kDa. GAPDH was used as an internal control. The values are expressed as the mean $\pm \mathrm{SD}$ Significantly different from control at ${ }^{*} \mathrm{p}<0.05$. 


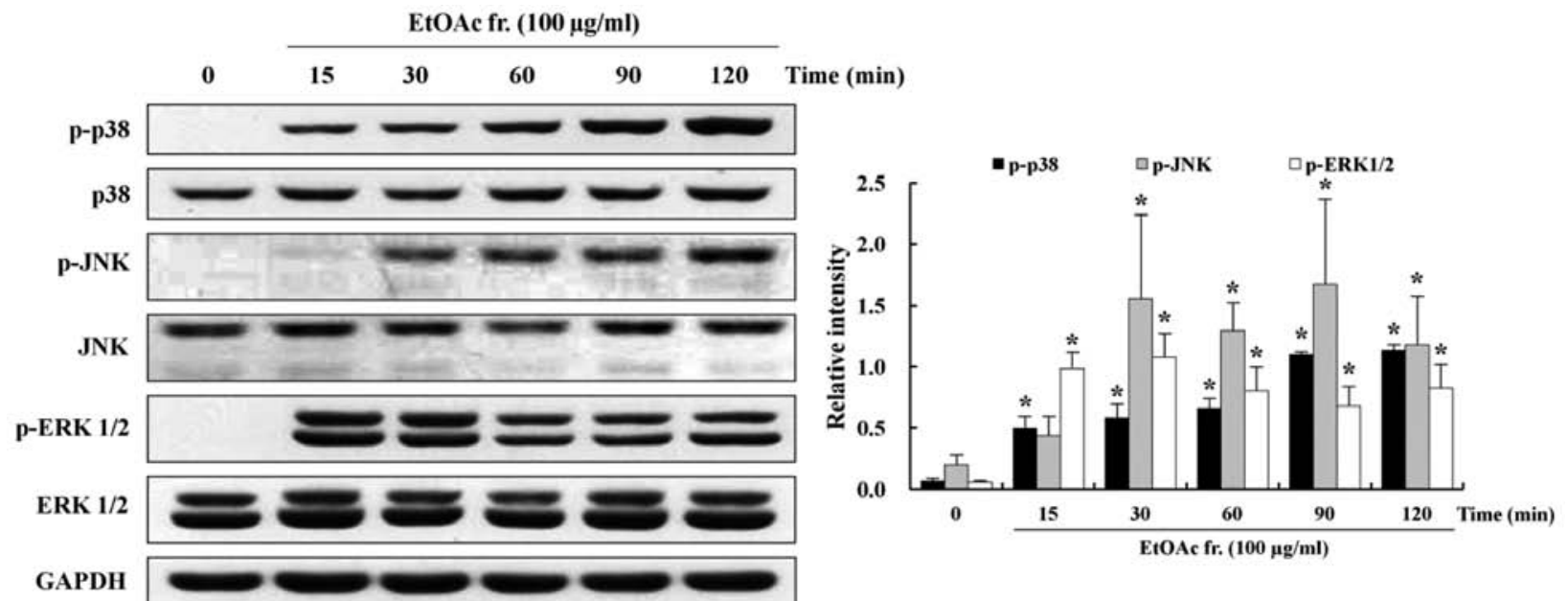

Figure 6. Effect of EtOAc fraction on the phosphorylation of p38, JNK and ERK1/2 in AGS cells. The cells were treated with EtOAc fraction (100 $\mu \mathrm{g} / \mathrm{ml})$ for the indicated times. Band density was quantitated and plotted on the bar graph. phospho-p38, p38, 43 kDa; phosphor-JNK, JNK, 46/54 kDa; phosphor-ERK1/2, ERK1/2, $42 / 44 \mathrm{kDa}$. GAPDH was used as an internal control. The values are expressed as the mean $\pm \mathrm{SD}$. Significantly different from control at ${ }^{*} \mathrm{p}<0.05$.

its expression in a time- and dose-dependent manner (Fig. 4A). Previous studies investigating the involvement of p53 in the cellular response to active substances from natural plants have shown that it induces apoptosis and upregulates p53 in various cancer cells (37). The p53 activation causes induction of apoptotic cell death, which leads to the release of cytochrome $\mathrm{c}$ from the mitochondria (38). There are 2 major apoptotic pathways: the intrinsic mitochondrial pathway and the extrinsic death receptor pathway $(39,40)$. Both these pathways are regulated by caspases for the cleavage of cellular proteins. The mitochondrial pathway induces apoptosis by releasing pro-apoptotic protein such as cytochrome $\mathrm{c}$. The mitochondrial-mediated apoptosis is regulated by apoptotic proteins that suppress the anti-apoptotic protein bcl-2 and promote the pro-apoptotic protein bax (41). We showed that the EtOAc fraction decreased the expression of bcl-2 and increased the expression levels of cytochrome $\mathrm{c}$ and bax/bcl-2 ratio in a time- and dose-dependent manner (Fig. 4B and $\mathrm{C}$ ). Cytochrome $\mathrm{c}$ is released from the mitochondria into the cytosol during apoptosis. The released cytochrome $\mathrm{c}$ forms an apoptosome composed of apoptotic protease activating factor-1 (Apaf1), cytochrome c, and caspase-9, which subsequently activates caspase-3 $(29,42)$. As one of the primary pathways of apoptosis, the mitochondrial pathway is regulated by bcl-2 family proteins and is finalized by DNA fragmentation, and the apoptotic bodies are regulated through the activation of caspase-3, a final executing factor. The death receptor pathway is initiated by Fas receptor that transduces apoptotic signals into caspase-8-dependent cascade (43). During this cascade, caspase- 8 induces the release of cytochrome $\mathrm{c}$ and activates caspase-3.

Several studies have provided evidence that caspase plays a crucial role in the induction of apoptosis $(44,45)$. Caspases are grouped into initiator caspases such as caspase- 8 and -9 and effector caspases such as caspase-3. Caspase-3 is an executioner caspase that is activated by a mitochondrial-mediated apoptosis involving caspase- 9 or a death receptor-mediated apoptosis involving caspase-8 (46). In the present study, procaspase- $3,-8$ and -9 , inactive forms of caspase, decreased in the cells treated with the EtOAc fraction in a time- and dose- dependent manner (Fig. 5A). In contrast, cleaved caspase-3, -8 and -9 , active forms of caspase, increased substantially in the cells treated with the EtOAc fraction in a time- and dose-dependent manner (Fig. 5A). In addition, pretreatment with the general caspase inhibitor Z-VAD-FMK significantly inhibited the EtOAc fraction-induced apoptosis, indicating that the EtOAc fraction induced caspase-dependent apoptosis in the AGS cells. The expression levels of caspase- 3 and -8 were significantly blocked in the presence of Z-VAD-FMK, but the inhibition of caspase- 9 had a mild inhibitory effect (Fig. 5B). Caspase-9 was activated at $\sim 6 \mathrm{~h}$, while caspase- 3 was activated at $4 \mathrm{~h}$. These findings indicate that caspase- 3 has a feedback action on caspase-9. These results suggested that p53 is a key regulator of apoptosis and cell cycle arrest in the EtOAc fraction-treated AGS cells. Furthermore, bcl-2 and anti-apoptotic protein was impeded by the release of cytochrome $\mathrm{c}$ from the mitochondria, and caspases were sequentially activated to induce apoptosis of the EtOAc fraction-treated AGS cells.

The MAPK signaling pathways regulate intracellular functions such as apoptosis and cell proliferation (47). Major members in the MAPK signaling pathway belong to 3 subgroups of the MAPK family: p38, JNK and ERK1/2 (48). Several studies have reported that the activation of MAPKs is linked to cell growth and induction of apoptosis in various cancer cells (49-51). It has been shown that activation of p38 and JNK are involved in mitochondrial-mediated apoptosis and caspase activation and that ERK1/2 is associated with cell proliferation and survival. This study hypothesized that the anticancer activity of the EtOAc fraction was related to the activation of the MAPK signaling pathway. To screen the MAPK-signaling pathway underlying the anticancer effects of the EtOAc fraction, the phosphorylation of p38, JNK and ERK 1/2 was determined. We observed that the EtOAc fraction increased phosphorylation of p38 and JNK in a time-dependent manner (Fig. 6).

In conclusion, we showed that the EtOAc fraction could effectively suppress the growth of AGS cells by the induction of apoptosis and cell cycle arrest. The expression levels 
of p53, cytochrome c, cleaved caspase-3, -8 and -9 were upregulated, and the expression levels of CDK1, cyclin B1, bcl-2, pro-caspase-3, -8 and -9 were downregulated through phosphorylation of p38 and JNK in the AGS cells treated with the EtOAc fraction. These results provide, for the first time, a useful foundation for understanding the anticancer effects of $O$.japonicus at the molecular level and show that $O$.japonicus could be used for the development of novel anticancer agents for the treatment of gastric cancers.

\section{Acknowledgements}

This study was supported by the Post-doctoral Research Program of Inje University 2012.

\section{References}

1. Kelloff GJ: Perspectives on cancer chemoprevention research and drug development. Adv in Cancer Res 78: 199-334, 2000.

2. Ryu DS, Baek GO, Kim EY, Kim KH and Lee DS: Effects of polysaccharides derived from Orostachys japonicus on induction of cell cycle arrest and apoptotic cell death in human colon cancer cells. BMB Rep 43: 750-755, 2010.

3. Choi SY, Chung MJ, Seo WD, Shin JH, Shon MY and Sung NJ: Inhibitory effects of Orostachys japonicus extracts on the formation of N-nitrosodimethylamine. J Agric Food Chem 54: 6075-6078, 2006.

4. Jung HJ, Choi J, Nam JH and Park HJ: Anti-ulcerogenic effects of the flavonoid-rich fraction from the extract of Orostachys japonicus in mice. J Med Food 10: 702-706, 2007.

5. Lee HS, Ryu DS, Lee GS and Lee DS: Anti-inflammatory effects of dichloromethane fraction from Orostachys japonicus in RAW 264.7 cells: Suppression of NF- $\mathrm{KB}$ activation and MAPK signaling. J Ethnopharmacol 140: 271-276, 2012.

6. Je Ma C, Jung WJ, Lee KY, Kim YC and Sung SH: Calpain inhibitory flavonoids isolated from Orostachys japonicus. J Enzyme Inhib Med Chem 24: 676-679, 2009.

7. Park HJ, Young HS, Park KY, Rhee SH, Chung HY and Choi JS: Flavonoids from the whole plants of Orostachys japonicus. Arch Pharm Res 14: 167-171, 1991.

8. Ryu DS, Lee HS, Lee GS and Lee DS: Effect of the ethylacetate extract of Orostachys japonicus on induction of apoptosis through the $\mathrm{p} 53$-mediated signaling pathway in human gastric cancer cells. Biol Pharm Bull 35: 660-665, 2012.

9. Singh SV, Herman-Antosiewicz A, Singh AV, Lew KL, Srivastava SK, Kamath R, Brown KD, Zhang L and Baskarah R: Sulforaphane-induced $\mathrm{G} 2 / \mathrm{M}$ phase cell cycle arrest involves checkpoint kinase 2-mediated phosphorylation of cell division cycle 25C. J Biol Chem 279: 25813-25822, 2004.

10. Harris SL and Levin AJ: The p53 pathway: positive and negative feedback loops. Oncogene 24: 2899-2908, 2005.

11. Vazquez A, Bond EE, Levine AJ and Bond GL: The genetics of the p53 pathway, apoptosis and cancer therapy. Nat Rev Drug Discov 7: 979-987, 2008.

12. Shiozaki EN and Shi Y: Caspases, IAPs and Smac/DIABLO: mechanisms from structural biology. Trends Biochem Sci 29: 486-494, 2004.

13. Tsujimoto Y: Bcl-2 family of proteins: life-or-death switch in mitochondria. Biosci Rep 22: 47-58, 2002.

14. Dhanalakshmi S, Agarwal P, Globe L and Agarwal R: Silibinin sensitizes human prostate carcinoma DU145 cells to cisplatinand carboplatin-induced growth inhibition and apoptotic death Int J Cancer 106: 699-705, 2003.

15. Brooks G: Cyclin, cyclin-dependent kinases, and cyclindependent kinase inhibitors: detection methods and activity measurements. Methods Mol Biol 296: 291-298, 2005.

16. Vermeulen K, Berneman ZN and Van Bockstaele DR: Cell cycle and apoptosis. Cell Prolif 36: 165-175, 2003.

17. Sebolt-Leopold JS: Development of anticancer drugs targeting the MAP kinase pathway. Oncogene 19: 6594-6599, 2000.

18. Sebolt-Leopold JS and Herrera R: Targeting the mitogenactivated protein kinase cascade to treat cancer. Nat Rev Cancer 4: 937-947, 2004.
19. Jeong JH, Ryu DS, Suk DH and Lee DS: Anti-inflammatory effects of ethanol extract from Orostachys japonicus on modulation of signal pathways in LPS-stimulated RAW 264.7 cells. BMB Rep 44: 399-404, 2011.

20. Lee HS, Bilehal D, Lee GS, Ryu DS, Kim HK, Suk DH and Lee DS: Anti-inflammatory effect of the hexane fraction from Orostachys japonicus in RAW 264.7 cells by suppression of NF- $\kappa \mathrm{B}$ and PI3K-Akt signaling. J Funct Foods 5: 1217-1225, 2013.

21. Kaufmann SH and Henqartner MO: Programmed cell death: alive and well in the new millennium. Trends Cell Biol 11: 526-534, 2001

22. Ryu DS, Kim SH and Lee DS: Anti-proliferative effect of polysaccharides from Salicornia herbacea on induction of G2/M arrest and apoptosis in human colon cancer cells. J Microbiol Biotechnol 19: 1482-1489, 2009.

23. Nakanishi M, Shimada N and Niida H: Genetic instability in cancer cells by impaired cell cycle checkpoints. Cancer Sci 97: 984-989, 2006

24. Elledge SJ and Harpae JW: CDK inhibitors; on the threshold of checkpoints and development. Curr Opin Cell Biol 6: 847-852, 1994.

25. Vousden KH: Apoptosis. p53 and PUMA: a deadly duo. Science 309: 1685-1686, 2005.

26. Lavin MF and Gueven N: The complexity of p53 stabilization and activation. Cell Death Differ 13: 941-950, 2006.

27. Ai Z, Lu W and Qin X: Arsenic trioxide induces gallbladder carcinoma cell apoptosis via down regulation of bcl-2. Biochem Biophys Res Commun 348: 1075-1081, 2006.

28. Wang JB, QI LL, Zheng SD and Wu TX: Curcumin induces apoptosis through the mitochondria-mediated apoptotic pathway in HT-29 cells. J Zhejizng Univ Sci B 10: 93-102, 2009.

29. Lavrik I, Golks A and Krammer PH: Death receptor signaling. J Cell Sci 118: 265-267, 2005.

30. Fujita E, Egashira J, Urase K, Kuida K and Momoi T: Caspase-9 processing by caspase-3 via a feedback amplification loop in vivo. Cell Death Differ 8: 335-344, 2001.

31. Seger R and Krebs EG: The MAPK signaling cascade. FASEB J 9: 726-735, 1995.

32. Meier P, Finch A and Evan G: Apoptosis in development. Nature 407: 796-801, 2000.

33. Evan GI and Vousden KH: Proliferation, cell cycle and apoptosis in cancer. Nature 411: 342-348, 2001.

34. Schwartz GK and Shah MA: Targeting the cell cycle: a new approach to cancer therapy. J Clin Oncol 23: 9408-9421, 2005.

35. Koff A, Giordano A, Desai D, Yamashita K, Harper JW, Elledge S, Nishimoto T, Morgan DO, Franza BR and Roberts JM: Formation and activation of a cyclin E-cdk 2 complex during the G1 phase of the human cell cycle. Science 257: 1689-1694, 1992.

36. Fisher DE: The p53 tumor suppressor: critical regulator of life \& death in cancer. Apoptosis 6: 7-15, 2001.

37. Moll UM and Zaika A: Nuclear and mitochondrial apoptotic pathways of p53. FEBS Lett 493: 65-69, 2001.

38. Erster S, Mihara M, Kim RH, Petrenko O and Moll UM: In vivo mitochondrial p53 translocation triggers a rapid first wave of cell death in response to DNA damage that can precede p53 target gene activation. Mol Cell Biol 24: 6728-6741, 2004.

39. Jiang $X$ and Wang $X$ : Cytochrome c-mediated apoptosis. Annu Rev Biochem 73: 87-106, 2004

40. Nagata S: Fas ligand-induced apoptosis. Annu Rev Genet 33: 29-55, 1999.

41. Willis SN and Adams JM: Life in the balance: how BH3-only proteins induce apoptosis. Curr Opin Cell Biol 17: 617-625, 2005.

42. Pop C, Timmer J, Sperandio S and Salvesen GS: The apoptosome activates caspase- 9 by dimerization. Mol Cell 22: 269-275, 2006

43. Zhou Z, Sun X and Kang YJ: Ethanol-induced apoptosis in mouse liver: Fas- and cytochrome c-mediated caspase-3 activation pathway. Am J Pathol 159: 329-338, 2001.

44. Jin UH, Song KH, Motomura M, Suzuki I, Gu YH, Kang YJ, Moon TC and Kim CH: Caffeic acid phenethyl ester induces mitochondria-mediated apoptosis in human myeloid leukemia U937 cells. Mol Cell Biochem 310: 43-48, 2008.

45. Zheng Y, Zhou M, Ye A, Li Q, Bai Y and Zhang Q: The conformation change of Bcl-2 is involved in arsenic trioxide-induced apoptosis and inhibition of proliferation in SGC7901 human gastric cancer cells. World J Sur Oncol 8: 31, 2010. 
46. Cho SH, Chung KS, Choi JH, Kim DH and Lee KT: Compound K, a metabolite of ginseng saponin, induces apoptosis via caspase8 -dependent pathway in HL-60 human leukemia cells. BMC Cancer 9: 449, 2009.

47. Martin GS: Cell signaling and cancer. Cancer Cell 4: 167-174, 2003.

48. Freeman SM and Whartenby KA: The role of the mitogenactivated protein kinase cellular signaling pathway in tumor cell survival and apoptosis. Drug News Perspect 17: 237-242, 2004.

49. Lin A and Dibling B: The true face of JNK activation in apoptosis. Aging Cell 1: 112-116, 2002.
50. Lunghi P, Giuliani N, Mazzera L, Lombardi G, Ricca M, Corradi A, Cantoni AM, Salvatore L, Riccioni R and Costanzo A: Targeting MEK/MAPK signal transduction module potentiates ATO-induced apoptosis in multiple myeloma cells through multiple signaling pathways. Blood 112: 2450-2462, 2008.

51. Mansouri A, Ridgway LD, Korapati AL, Zhang Q, Tian L, Wang Y, Siddik ZH, Mills GB and Claret FX: Sustained activation of JNK/p38 MAPK pathways in response to cisplatin leads to Fas ligand induction and cell death in ovarian carcinoma cells. J Biol Chem 278: 19245-19256, 2003. 